\title{
Changes in fermentation and biohydrogenation intermediates in continuous cultures fed low and high levels of fat with increasing rates of starch degradability
}

\author{
G. J. Lascano, M. Alende, L. E. Koch, and T. C. Jenkins ${ }^{1}$ \\ Department of Animal and Veterinary Sciences, Clemson University, Clemson, SC 29634
}

\begin{abstract}
Excessive levels of starch in diets for lactating dairy cattle is a known risk factor for milk fat depression, but little is known about how this risk is affected by differences in rates of starch degradability $\left(\mathrm{K}_{\mathrm{d}}\right)$ in the rumen. The objective of this study was to compare accumulation of biohydrogenation intermediates causing milk fat depression, including conjugated linoleic acid (CLA), when corn with low or high $\mathrm{K}_{\mathrm{d}}$ were fed to continuous cultures. Diets contained (dry matter basis) $50 \%$ forage (alfalfa pellets and grass hay) and $50 \%$ concentrate, with either no added fat (LF) or $3.3 \%$ added soybean oil (HF). Within both the LF and HF diets, 3 starch degradability treatments were obtained by varying the ratio of processed (heat and pressure treatments) and unprocessed corn sources, giving a total of 6 dietary treatments. Each diet was fed to dual-flow continuous fermenters 3 times a day at 0800, 1600, and 2400 h. Diets were fed for four 10-d periods, with $7 \mathrm{~d}$ for adaptation and $3 \mathrm{~d}$ for sample collection. Orthogonal contrasts were used in the GLIMMIX procedure of SAS to test the effects of fat, starch degradability, and their interaction. Acetate and acetate:propionate were lower for $\mathrm{HF}$ than for LF but daily production of trans-10 18:1 and trans-10,cis-12 CLA were higher for HF than for LF. Increasing starch $\mathrm{K}_{\mathrm{d}}$ from low to high increased culture $\mathrm{pH}$, acetate, and valerate but decreased butyrate and isobutyrate. Changes in biohydrogenation intermediates (expressed as \% of total isomers) from low to high starch $\mathrm{K}_{\mathrm{d}}$ included reductions in trans-11 18:1 and cis-9,trans-11 CLA but increases in trans-10 18:1 and trans-10,cis-12 CLA. The results show that increasing the starch $K_{d}$ in continuous cultures while holding starch level constant causes elevation of biohydrogenation intermediates linked to milk fat depression. Key words: lipid, biohydrogenation, starch degradability, continuous cultures
\end{abstract}

Received February 15, 2016.

Accepted April 27, 2016.

${ }^{1}$ Corresponding author: TJNKNS@clemson.edu

\section{INTRODUCTION}

Diet-induced milk fat depression (MFD) continues to have a major economic effect on the dairy industry giving high priority to developing dietary strategies that restore milk fat yield. Recent research results link MFD with the formation of bioactive trans fatty acid intermediates produced from biohydrogenation $(\mathbf{B H})$ of unsaturated fatty acids by the rumen microbial population (Jenkins and Harvatine, 2014). Among the most potent intermediates causing MFD are several CLA isomers, such as trans-10,cis-12. Baumgard et al. (2000) reported that trans-10,cis-12 infused postruminally in lactating dairy cows decreased milk fat content $42 \%$ and milk fat yield $48 \%$. Trans-9,cis-11 CLA and cis-10,trans-12 CLA were also reported to inhibit milk fat synthesis in dairy cows (Saebø et al., 2005; Perfield et al., 2007) with the former causing a $15 \%$ reduction in milk fat yield.

Changes in the ruminal environment initiated through the diet can lead to a microbial population shift that is accompanied by a change in the type of CLA produced. For example, increasing UFA concentration in the rumen can cause rapid and dramatic microbial shifts (Rico et al. 2015) and elevate ruminal concentration of the trans-10, cis-12 CLA isomer. Addition of $3.6 \%$ soybean oil to a diet fed to continuous cultures of mixed ruminal microorganisms caused several fold increases in the daily production of trans-10 C18:1 and trans-10,cis-12 CLA (Jenkins et al., 2014). Low rumen $\mathrm{pH}$ is another key factor contributing to a microbial shift and the type of CLA produced. Lowering $\mathrm{pH}$ in continuous cultures caused an increase in the concentration of trans-10, cis-12 CLA but no change in cis-9,trans-11 CLA (Fuentes et al., 2009). Qiu et al. (2004) reported that reduced ruminal $\mathrm{pH}$ can affect microbial populations, especially cellulolytic bacteria. Total cellulolytic bacterial numbers were reduced, accompanied by reduced acetate:propionate and altered $\mathrm{BH}$ when $\mathrm{pH}$ was low.

Also, high starch diets can affect the types of BH intermediates that accumulate in ruminal contents. High 
starch diets shift BH pathways in continuous cultures, causing an increase in concentrations of trans-10 18:1 and trans-10,cis-12 CLA intermediates (Gudla et al., 2012). Combinations of high starch and high fat often reduce milk fat synthesis more than feeding the same amount of starch or fat alone (Zened et al., 2013). This might be attributed to starch and fat targeting different points in $\mathrm{BH}$ where one has a greater effect on shifting the pathway toward trans-10,cis-12 CLA production and the other acts more to inhibit the final step in the pathway, allowing trans-10,cis-12 CLA to accumulate in ruminal contents.

Source of starch may also be a factor affecting the intensity of starch-fat interactions on $\mathrm{BH}$. In some reports, starch sources with faster rates of degradation yield higher trans intermediates than sources with slower rates of degradation at any given level of added fat. For example, substitution of barley for corn caused an increase in trans-10 C18:1 concentrations in ruminal contents from continuous cultures (Jenkins et al., 2003). The objective of this investigation was to determine if varying the rates of starch degradability while maintaining a constant starch level in high or low fat diets fed to continuous cultures had an effect on the type of $\mathrm{BH}$ intermediates produced.

\section{MATERIALS AND METHODS}

\section{Treatments}

The study was a randomized complete block design consisting of 7 experimental diets fed to 7 dual-flow continuous fermenters. Fermenters were fed either 54 $\mathrm{g}$ of $\mathrm{DM} / \mathrm{d}$ of a $0 \%$ soybean oil diet $(\mathbf{L F})$ or $55.7 \mathrm{~g}$ of $\mathrm{DM} / \mathrm{d}$ of a $3.3 \%$ soybean oil diet $(\mathbf{H F})$, divided equally among 3 feedings at 0800, 1600, and $2400 \mathrm{~h}$. The higher feeding rate for $\mathrm{HF}$ maintained the same nutrient input into the fermenters as LF except for fatty acids (Table 1). Within both the LF and HF diets, 3 starch degradability treatments were obtained by varying the ratio of processed and unprocessed corn sources obtained from Matrix Nutrition LLC, Phoenix, Arizona (Table 2 ). One corn source was received from the supplier as whole corn with no prior processing (unprocessed) and was then ground within $3 \mathrm{~d}$ of receipt to pass a $2-\mathrm{mm}$ sieve in a centrifugal mill. The second corn source was received in finely ground particle size and was reported by the supplier to have been prepared from the unprocessed whole corn. The supplier stated that processing involved proprietary heat and pressure treatments that sheared the prolamine protein structure, which eliminated the crystalline and hydrophobic properties of the vitreous unprocessed corn. For this study, the term unprocessed refers to the whole corn sample and
Table 1. Diet composition and nutrient inputs into fermenters for the low fat (LF) and high fat (HF) diets

\begin{tabular}{lcc}
\hline Item & LF & HF \\
\hline Ingredient, \% of DM & & \\
Alfalfa pellets & 32.9 & 31.8 \\
Ground hay & 16.6 & 16.1 \\
Ground corn & 33.3 & 32.2 \\
Soybean meal & 8.5 & 8.2 \\
Soy hulls & 8.7 & 8.4 \\
Soybean oil & 0.0 & 3.3 \\
Nutrient input per fermenter, g/d & 54.0 & 55.7 \\
DM & & \\
CP & 10.5 & 10.1 \\
NDF & 21.3 & 21.4 \\
ADF & 18.0 & 19.2 \\
Starch & 13.0 & 12.8 \\
Fatty acids & 1.01 & 2.73 \\
\hline
\end{tabular}

${ }^{1}$ Nutrients supplied by LF and HF diets were equalized by adjusting diet composition and amounts fed to provide the same nutrient input (except fatty acids) into each fermenter per day.

processed refers to the same whole corn subjected to the heat and pressure treatment as received and before they were ground at Clemson University.

After grinding, both the unprocessed and processed corn sources were analyzed for rates of starch degradability in a 7 -h in vitro test performed by Cumberland Valley Analytical Services (Hagerstown, MD). The high starch degradability treatment $(\mathbf{H I})$ was obtained by addition of only the ground processed corn grain in the diet, which analyzed at $80 \%$ starch degradability in the 7-h in vitro test. The low starch degradability treatment $(\mathbf{L O})$ contained only the ground unprocessed corn grain in the diets, which analyzed at $48 \%$ starch degradability in the 7-h in vitro test. An intermediate level of starch degradability (MED) was a 50:50 mix of the same processed and unprocessed corn sources.

The expectation was that the HI treatment would lower culture $\mathrm{pH}$ and that might account for any observed differences in the pattern of $\mathrm{BH}$ intermediates. To determine the influence of a $\mathrm{pH}$ drop, a seventh treatment was tested that fed the HF-HI diet to a culture flask, but $\mathrm{pH}$ of this flask was adjusted daily

Table 2. Composition of unprocessed and processed corn sources used in dietary treatments to vary rates of starch degradability

\begin{tabular}{lcc}
\hline Item & $\begin{array}{c}\text { Unprocessed } \\
\text { corn }^{1}\end{array}$ & $\begin{array}{c}\text { Processed } \\
\text { corn }\end{array}$ \\
\hline DM, \% & 87.7 & 87.9 \\
CP, \% of DM & 8.6 & 7.9 \\
Soluble protein, \% of DM & 0.5 & 0.9 \\
ADF, \% of DM & 1.3 & 2.4 \\
NDF, \% of DM & 2.7 & 3.3 \\
Starch, \% of DM & 82.5 & 82.3 \\
7-h starch degradability, \% of starch & 48.4 & 84.0 \\
\hline
\end{tabular}

${ }^{1}$ Unprocessed and processed corn sources were supplied by Mark Holt of Matrix Nutrition LLC (Phoenix, AZ). 
to equal $\mathrm{pH}$ of the LF-LO starch treatment. This gave $2 \mathrm{HF}-\mathrm{HI}$ starch degradability treatments: HF-HI where $\mathrm{pH}$ was permitted to fluctuate on its own, and HF-HI2 where $\mathrm{pH}$ was matched to the LF-LO treatment. Each treatment was randomly assigned to 1 of 7 dual-flow continuous fermenters with 4 periods run for each treatment. Each period was started with a clean fermenter and inoculated with fresh ruminal contents from a fistulated cow.

\section{Continuous Culture Conditions}

Whole ruminal contents were collected from a ruminally fistulated Holstein cow $2 \mathrm{~h}$ after being fed a $50 \%$ forage: $50 \%$ concentrate diet. All surgical and animal care protocols were approved by the Clemson University Animal Care and Use Committee. Within 20 min of collection, large particles were removed from the whole ruminal contents by filtration through 2 layers of cheesecloth, and the filtrate containing the microbial population was transferred immediately to the laboratory in a sealed container. With constant stirring, the filtered ruminal inoculum was diluted 1:1 with buffer (Slyter et al., 1966) and then added to completely fill (approximately $800 \mathrm{~mL}$ ) each dual-flow fermenter that was modified in construction and operation from the design described by Teather and Sauer (1988). The main modifications were a reconfigured overflow sidearm that angled downward at approximately $45^{\circ}$ to facilitate emptying, a faster stirring rate $(45 \mathrm{rpm})$ that still allowed stratification of particles into an upper mat, a middle liquid layer of small feed particles, and a lower layer of dense particles, and a higher feeding rate $(60 \mathrm{~g} / \mathrm{d}$ as fed). The culture was maintained for $10 \mathrm{~d}$ (7 $\mathrm{d}$ for adaptation and the last $3 \mathrm{~d}$ for sampling).

Buffer solution (Slyter et al., 1966) was delivered continuously using a peristaltic pump to achieve a $0.10 / \mathrm{h}$ fractional dilution rate. Buffer was prepared each day before the am feeding in sufficient quantity for all fermenters to last $24 \mathrm{~h}$, and was titrated each morning with sufficient $6 \mathrm{~N} \mathrm{NaOH}$ or $3 \mathrm{~N} \mathrm{HCl}$ to maintain $\mathrm{pH}$ of the LF-LO treatment within a working range of $\mathrm{pH} 6.0$ to 6.5. Because all fermenters received the same buffer adjusted only for the LF-LO treatment, treatment effects of fat and starch degradability had the opportunity to alter $\mathrm{pH}$. The only exception was the HF-HI2 treatment that had its own separate buffer that was titrated each morning to match $\mathrm{pH}$ of LF-LO. The fermenters were continuously gassed with $\mathrm{CO}_{2}$ at a rate of $20 \mathrm{~mL} / \mathrm{min}$ to maintain anaerobic conditions. The temperature of the fermenters were held at $39^{\circ} \mathrm{C}$ by a circulating water bath.

Culture $\mathrm{pH}$ was monitored daily by taking $\mathrm{pH}$ readings (Hanna Instruments Inc., Woonsocket, RI) just before the 0800, 1600, and $2400 \mathrm{~h}$ feedings. A 4-mL sample of culture contents were taken on d 10 of each period at $4 \mathrm{~h}$ after feeding for analysis of VFA. Culture contents were thoroughly mixed $(155 \mathrm{rpm})$ before $\mathrm{pH}$ readings or sampling. On d 7, 8, and 9 of each period, overflow from each fermenter was collected in a 2-L Erlenmeyer flask kept in a covered ice bath. After recording total volume, a $20 \%$ sample of the overflow was composited over sampling times and immediately frozen. Frozen samples were later thawed and a subsample was lyophilized. Overflow contents were mixed continuously with a magnetic stir bar during sampling.

\section{Sample Analysis}

Forage, concentrate, and dried overflow samples were ground in a centrifugal mill through a $0.5-\mathrm{mm}$ sieve. Ground samples were analyzed for $\mathrm{DM}\left(100^{\circ} \mathrm{C}\right)$, Kjeldahl N (Association of Official Analytical Chemists, 1990), NDF, ADF (Van Soest et al., 1991), and fatty acids. Culture samples for VFA analysis were pipetted $(4 \mathrm{~mL})$ into polycarbonate tubes containing $1 \mathrm{~mL}$ of $25 \%$ (wt/ wt) metaphosphoric acid, mixed, and then centrifuged at $40,000 \times g$ for $20 \mathrm{~min}$ at $4^{\circ} \mathrm{C}$. After centrifugation, $1-\mathrm{mL}$ of the supernatant was combined with $0.1-\mathrm{mL}$ internal standard $(86 \mu \mathrm{mol}$ of 2-ethylbutyric acid $/ \mathrm{mL})$. Samples were injected into a Hewlett-Packard 5890A gas chromatograph equipped with a NUKOL fused silica capillary column $(30 \mathrm{~m} \times 0.25 \mathrm{~mm})$ with $0.25 \mu \mathrm{m}$ film thickness (Supelco Inc., Bellefonte, PA).

Long-chain fatty acids in ground feed and overflow samples were converted to methyl esters by direct transesterification in sodium methoxide and methanolic $\mathrm{HCl}$ (Jenkins, 2010). An internal standard (2 mg of heptadecanoic acid) was added at the start of methylation to quantify fatty acid masses. Quantities of individual fatty acids present in the cultures were determined on a Hewlett-Packard 5890A gas chromatograph equipped with a P-2380 fused silica capillary column $(100 \mathrm{~m} \times$ $0.25 \mathrm{~mm}$ ) with $0.2-\mu \mathrm{m}$ film thickness (Supelco Inc.). The conditions used were initially $140^{\circ} \mathrm{C}$ for 3 min with a gradual increase of $3.7^{\circ} \mathrm{C}$ per min up to $220^{\circ} \mathrm{C}$ holding for 20 min. Helium was used as the carrier gas at 20 $\mathrm{cm} / \mathrm{s}$. Identities of peaks were determined by comparison of retention times to known standards.

\section{Statistics}

The analysis of the response variables was based on a model for a randomized complete block design. The blocks were based on periods and fermenters. The model included fixed effects for treatment and random effects for period and fermenter. The model for $\mathrm{pH}$ included treatment effects as well as fixed effects for subsampling 
times and time interactions, and the additional random effect treatment and period interaction. All statistics were done with SAS version 9.4 (SAS Institute Inc., Cary, NC) using the Glimmix procedure for generalized mixed models with random effects.

Treatment effects were evaluated by the following orthogonal contrasts: (1) the main effect of fat, (2) the linear effect of starch degradability, (3) the quadratic effect of starch degradability, (4) the fat $\times$ starch interaction, and (5) HF-HI vs HF-HI2. Contrast probabilities are shown in tables if values were $\leq 0.15$. Contrast probabilities $\leq 0.05$ were considered significant, whereas those within 0.15 and 0.05 were considered trends.

Inspection of $\mathrm{pH}$ values at the conclusion of the study revealed that the HI treatments increased $\mathrm{pH}$ instead of decreasing $\mathrm{pH}$ as expected. Therefore, the HF-HI2 treatment was removed from the analysis because it had identical $\mathrm{pH}$ values to HF-HI and none of the HFHI vs HF-HI2 contrasts were significant $(P>0.05)$. The final analysis included data from the remaining 6 treatments.

\section{RESULTS AND DISCUSSION}

\section{Fat Effect}

Diets contained 2 fat levels in this investigation to determine if starch degradability effects on the production of $\mathrm{BH}$ intermediates differed depending on the intake of UFA. The $3.3 \%$ added soybean oil was intended to alter fermentation and the $\mathrm{BH}$ pathways with the expectation of causing an accumulation of trans-10 18:1 and trans-10,cis-12 CLA isomers. Starch degradability effects could then be monitored in cases of both normal and high trans-10 BH intermediates.

Total VFA concentrations and apparent digestibilities of DM and ADF were not different for LF and HF (Table 3). Acetate and acetate:propionate were lower $(P<0.05)$ and butyrate tended $(P=0.14)$ to be lower for HF compared with LF. Compared with LF, the HF treatment increased $(P<0.01)$ daily outflows of total fatty acids and all individual saturated and unsaturated fatty acids (Table 4) except for causing a decrease $(P$ $<0.01)$ in outflow of 12:0. No difference was found between LF and HF in outflow of 14:0. Biohydrogenation, expressed as fatty acid loss as a percentage of fatty acid input, was higher $(P<0.05)$ for HF than LF in the case of 18:2 but tended to be lower $(P=0.09)$ for 18:3. Daily production of all trans-C18:1 and CLA isomers was higher $(P<0.01)$ for HF than for LF (Table 5 ). Culture $\mathrm{pH}$ was not affected $(P>0.05)$ by the addition of fat to the diet averaging 6.16 and $6.09(\mathrm{SEM}=0.06)$ over the last $3 \mathrm{~d}$ of each period for the LF and HF diets, respectively (data not shown).

Overall, oil addition in this study gave similar fermentation and $\mathrm{BH}$ responses that have been reported previously. For example, addition of $3.64 \%$ soybean oil had the same responses in a previous continuous culture study including reduced acetate:propionate and increased daily production of $\mathrm{BH}$ intermediates including trans C18:1 and CLA (Jenkins et al., 2014). Feeding $5 \%$ sunflower oil to dairy cows increased total trans C18:1 from 8.9 to $28.0 \%$ of total ruminal fatty acids and increased CLA from 0.4 to $2.8 \%$ of ruminal fatty acids (Zened et al., 2013). The expectation of adding $3.3 \%$ soybean oil to the diet to increase daily produc-

Table 3. Effects of fat level and starch source on apparent digestibility and VFA in culture contents for samples taken at $4 \mathrm{~h}$ after the morning feeding on the last day of each period $(\mathrm{d} 10)^{1}$

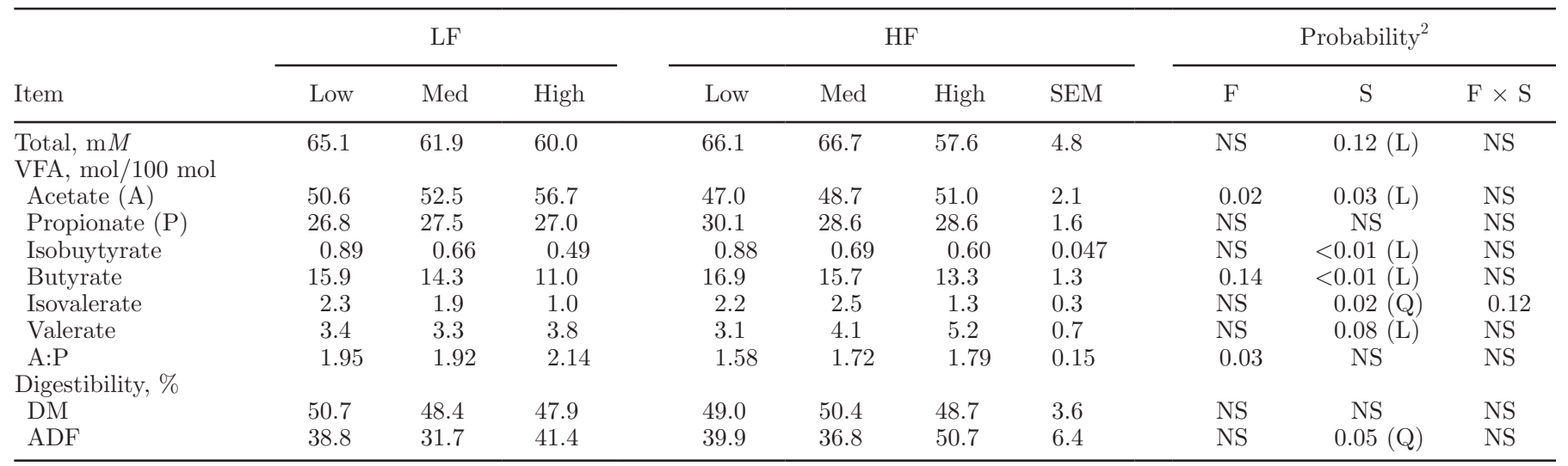

${ }^{1} \mathrm{LF}=$ no added fat; $\mathrm{HF}=3.3 \%$ added soybean oil; low $=$ low starch degradability diet containing only unprocessed corn; Med $=$ medium starch degradability diet using a 50:50 mix of unprocessed and processed corn; high = high starch degradability diet using only processed corn. ${ }^{2} P \leq 0.15$ are shown for fat $(\mathrm{F})$, starch degradability $(\mathrm{S})$, or fat by starch degradability interaction $(\mathrm{F} \times \mathrm{S})$. Linear $(\mathrm{L})$ or quadratic $(\mathrm{Q})$ polynomials are shown in parentheses for the $\mathrm{S}$ effect. 
Table 4. Effects of fat level and starch degradability on outflow $(\mathrm{mg} / \mathrm{d})$ of major saturated and unsaturated fatty acids from fermentors ${ }^{1}$

\begin{tabular}{|c|c|c|c|c|c|c|c|c|c|c|}
\hline Item & \multicolumn{3}{|c|}{$\mathrm{LF}$} & \multicolumn{4}{|c|}{$\mathrm{HF}$} & \multicolumn{3}{|c|}{ Probability $^{2}$} \\
\hline \multicolumn{11}{|c|}{ Saturated } \\
\hline $14: 0$ & 22.8 & 19.8 & 15.6 & 20.2 & 18.6 & 12.3 & 2.5 & NS & $<0.05(\mathrm{~L})$ & NS \\
\hline $16: 0$ & 191.9 & 188.3 & 161.9 & 306.2 & 329.9 & 272.2 & 24.0 & $<0.01$ & NS & NS \\
\hline 18:0 & 279.1 & 290.0 & 263.3 & 350.2 & 685.3 & 424.9 & 77.6 & $<0.01$ & $<0.05(\mathrm{Q})$ & 0.06 \\
\hline $18: 1$ & 56.5 & 67.8 & 69.1 & 199.9 & 229.5 & 205.6 & 23.1 & $<0.01$ & NS & NS \\
\hline $18: 2$ & 94.5 & 116.3 & 129.1 & 266.4 & 355.4 & 335.9 & 42.0 & $<0.01$ & $0.14(\mathrm{~L})$ & NS \\
\hline $18: 3$ & 26.2 & 31.9 & 33.0 & 39.4 & 52.4 & 48.1 & 5.9 & $<0.01$ & $0.08(\mathrm{~L})$ & NS \\
\hline Total & 829 & 874 & 820 & 1,904 & 2,298 & 1,929 & 165 & $<0.01$ & NS & NS \\
\hline \multicolumn{11}{|c|}{ Biohydrogenation ${ }^{3}$} \\
\hline $18: 2$ & 71.8 & 62.5 & 55.4 & 82.3 & 62.7 & 72.7 & 5.4 & $<0.01$ & $0.03(\mathrm{Q})$ & 0.05 \\
\hline $18: 3$ & 91.7 & 88.9 & 88.1 & 90.3 & 85.1 & 87.5 & 1.8 & 0.09 & $0.05(\mathrm{Q})$ & NS \\
\hline
\end{tabular}

${ }^{1} \mathrm{LF}=$ no added fat; $\mathrm{HF}=3.3 \%$ added soybean oil; low $=$ low starch degradability diet containing only unprocessed corn; Med $=$ medium starch degradability diet using a 50:50 mix of unprocessed and processed corn; high = high starch degradability diet using only processed corn. ${ }^{2} P \leq 0.15$ are shown for fat $(\mathrm{F})$, starch degradability $(\mathrm{S})$, or fat by starch degradability interaction $(\mathrm{F} \times \mathrm{S})$. Linear $(\mathrm{L})$ or quadratic $(\mathrm{Q})$ polynomials are shown in parentheses for the S effect.

${ }^{3}$ Expressed as milligrams of input - milligrams of outflow/milligrams of input for 18:2 and for 18:3.

tion of $\mathrm{BH}$ intermediates was successful and allowed assessment of starch degradability effects in conditions of both low and high trans-10 intermediate levels.

\section{Starch Effect}

By design, $\mathrm{pH}$ of the LF-LO treatment was maintained within the range of 6 to 6.5 by daily titration of the infusion buffer with $\mathrm{HCl}$ or $\mathrm{NaOH}$ (Figure 1), permitting an acceptable $\mathrm{pH}$ range for growth and function of the mixed microbial population. The same buffer was then used for the remainder of the day for all other culture flasks, allowing treatments to alter $\mathrm{pH}$ on their own. Culture $\mathrm{pH}$ was the same for all treatments on d 0 because each fermenter was filled from a common mixed pool of ruminal inoculum and buffer.

Table 5. Effects of fat level and starch degradability on major biohydrogenation intermediates expressed in milligrams per day outflow and as percentage of total ${ }^{1}$

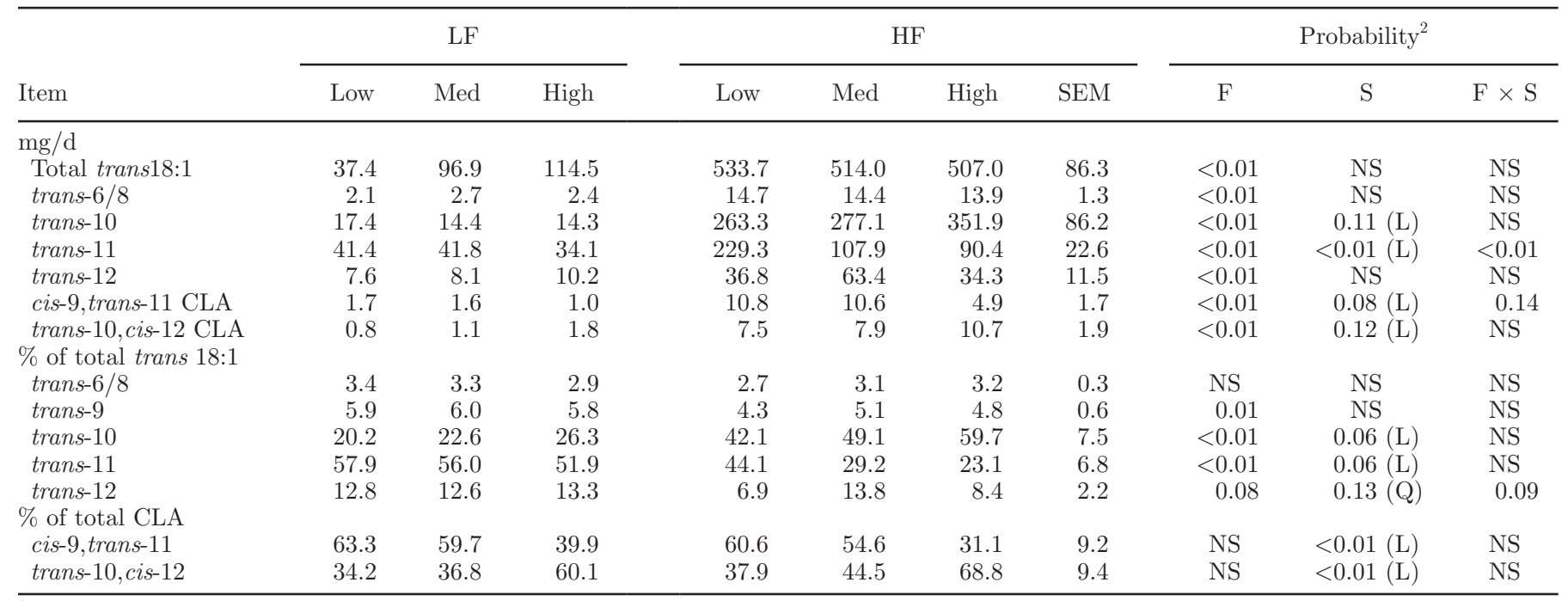

${ }^{1} \mathrm{LF}=$ no added fat; $\mathrm{HF}=3.3 \%$ added soybean oil; low $=$ low starch degradability diet containing only unprocessed corn; Med $=$ medium starch degradability diet using a 50:50 mix of unprocessed and processed corn; high = high starch degradability diet using only processed corn. ${ }^{2} P \leq 0.15$ are shown for fat $(\mathrm{F})$, starch degradability $(\mathrm{S})$, or fat by starch degradability interaction $(\mathrm{F} \times \mathrm{S})$. Linear $(\mathrm{L})$ or quadratic $(\mathrm{Q})$ polynomials are shown in parentheses for the $\mathrm{S}$ effect. 


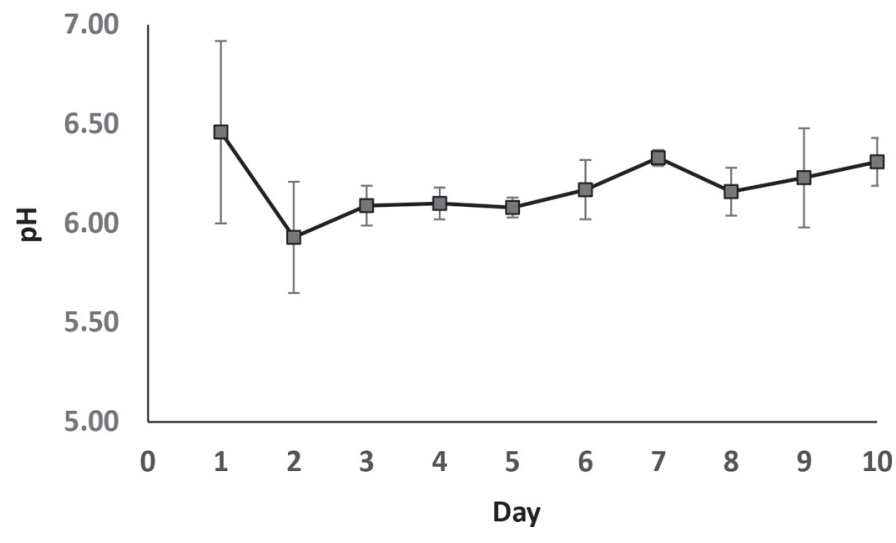

Figure 1. Mean $\mathrm{pH}$ values $( \pm \mathrm{SD})$ at $0 \mathrm{~h}$ (just before the $0800 \mathrm{~h}$ feeding) in fermenters by day of incubation for the LF and low starch degradability treatment that contained only unprocessed corn. LF = no added soybean oil; low $=$ low starch degradability diet containing only unprocessed corn.

By the end of $\mathrm{d} 1$, $\mathrm{pH}$ differed among the starch treatments with the $\mathrm{HI}$ treatment having the highest $\mathrm{pH}$ throughout the 10-d period (Figure 2).

A higher culture $\mathrm{pH}$ for diets with higher rates of starch degradability is counter to the common belief that increasing carbohydrate fermentability increases short-chain fatty acid production and the risk of ruminal acidosis (Broderick, 2003; Chibisa et al., 2015). For example, replacing dry shelled corn with high moisture corn to increase ruminally fermentable carbohydrate decreased mean ruminal $\mathrm{pH}$ from 5.82 to 5.67 and increased time spent below pH 5.8 from 4.4 to $6.4 \mathrm{~h} / \mathrm{d}$

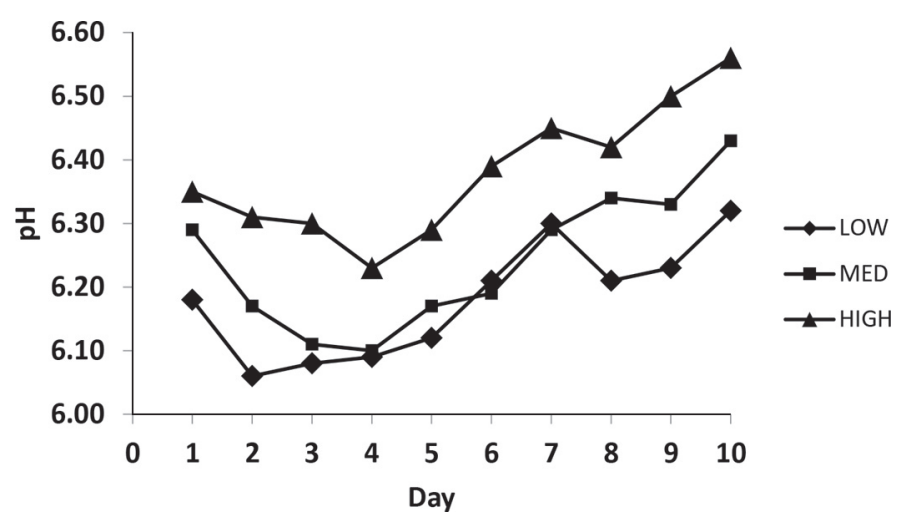

Figure 2. Mean pH values in fermenters by day for the low, medium, and high starch degradability treatments with each point averaged over both fat levels and times after feeding. Pooled SEM for each value was 0.064 . Significant effects were $\operatorname{starch}(P=0.02)$ and day $(P$ $\leq 0.01)$. The starch $\times$ day interaction was not significant $(P=0.42)$. Low $=$ low starch degradability diet containing only unprocessed corn; Med $=$ medium starch degradability diet using a 50:50 mix of unprocessed and processed corn; high = high starch degradability diet using only processed corn.
(Krause and Combs, 2003). Dijkstra et al. (2012) also noted an increased risk of ruminal acidosis as the rate of starch degradation increases.

Conversely, other studies reported that replacing corn starch with more rapidly fermented sugar did not cause a drop in ruminal $\mathrm{pH}$ in lactating cows (Broderick et al., 2008) and even caused an increase in ruminal $\mathrm{pH}$ (Martel et al., 2011). The increase in rumen $\mathrm{pH}$ from feeding rapidly fermented carbohydrate to cows could be partially explained by a butyrate-induced increase in permeability of ruminal epithelia upregulating the absorption of acetate and propionate (Chibisa et al., 2015). Supplementing barley with sugar from dried whey permeate in the Chibisa et al. (2015) study increased the molar proportion of butyrate (10.4 to 12.1) and also increased the chloride competitive absorption of total VFA (0.12 to $237.8 \mathrm{mmol} / \mathrm{h}$ ). However, in the current study butyrate proportions decreased from 16.9 to $13.3 \mathrm{~mol} / 100 \mathrm{~mol}(P<0.01)$, along with decreasing proportions of isobutyrate and isovalerate $(P<0.01)$, and a tendency to decrease $(P=0.12)$ total VFA when starch degradability went from LO to HI (Table 3 ). Interestingly, higher starch degradability increased $(P=0.03)$ acetate and tended to increase $(P=0.08)$ valerate proportions with a concurrent linear increase in ADF digestibility $(P<0.05)$ when degradability of starch was increased (Table 3).

With no possibility of enhanced acid absorption explaining the $\mathrm{pH}$ increase observed in the continuous fermenters in this study, an alternative explanation for the $\mathrm{pH}$ increase might be related to starch degradability effects on $\mathrm{N}$ utilization. Increased starch fermentability is expected to increase energy availability, which may allow for a more efficient utilization of organic acids for synthesis of microbial protein. Consistent with this explanation, microbial protein synthesis increased in continuous cultures when starch was replaced with sugar (Stokes et al., 1991), and in lactating dairy cows ruminal $\mathrm{NH}_{3}-\mathrm{N}$ concentrations were decreased when starch was replaced with sugars (McCormick et al., 2001) or with dried whey permeate (Chibisa et al., 2015). The linear decrease in total VFA concentrations caused by increased starch fermentability is consistent with the possible utilization of organic acids for synthesis of microbial protein and increased ADF digestion observed in this experiment. The effect of starch degradability on bacterial $\mathrm{N}$ synthesis was not the objective of this study and therefore was not determined. Alternatively, it has been suggested that protozoa can engulf starch granules and convert sugars to stored glycogen, resulting in a slower fermentation rate to VFA (Goad et al., 1998). However, it has to be considered that not all protozoa have the same capacity and preference to engulf starch 
and other highly fermentable carbohydrates (i.e., entodiniomorphid vs. isotrich; Nagaraja and Titgemeyer, 2007). Thus, the increase in ruminal pH could be explained by HI triggering a selective increase in starch utilizing protozoa numbers that did not occur in LO.

Major fatty acids in outflow were 16:0, which was not affected by starch degradability, and 18:0, which showed a fat $\times$ starch degradability interaction $(P=$ 0.06; Table 4). It is unclear why the MED treatment had higher 18:0 flow than either the LO or HI treatments. Flows of all other SFA (12:0, 14:0, and 20:0) decreased $(P<0.05)$ from LO to HI starch degradability.

Outflows of 18:2 and 18:3 from the fermenters increased $(P<0.05)$ from LO to HI, resulting in lower $(P$ $<0.05$ ) extents of $\mathrm{BH}$ as starch degradability increased (Table 4). Previous reports of reduced ruminal BH with increasing grain and starch intake have been frequent. Both lipolysis and $\mathrm{BH}$ were reduced in cows switched from a high to a low forage diet (Latham et al., 1972). Gerson et al. (1985) also reported reduced rates of lipolysis and $\mathrm{BH}$ with increasing starch addition to rumen in vitro cultures. More recently, high starch diets increased 18:2 concentrations in continuous cultures (Gudla et al., 2012). Reductions in rates of lipolysis and $\mathrm{BH}$ from starch are often attributed to the greater fermentation of starch lowering rumen $\mathrm{pH}$ (Van Nevel and Demeyer, 1996). In this study, BH of 18:2 declined despite similar starch levels and higher $\mathrm{pH}$ in going from LO to HI starch degradability. Fewer studies have examined the effect of starch degradability on BH. In a study with lactating dairy cows, feeding steam-flaked corn with higher rates of starch degradability had no effect on extent of BH (Mathew et al., 2011). However, studies using dry and lactating cows fed high fat and high starch diets reported no effects on rumen $\mathrm{pH}$, but increased rumen accumulation of trans-10 isomers (Zened et al., 2013; Ramirez Ramirez et al., 2015).

In addition to reducing extent of $\mathrm{BH}$, increasing starch degradability also altered the pattern of some BH intermediates (Table 5). No effects were found of starch degradability on daily production of total trans 18:1 or the trans- $6 / 8$ and trans- 12 positional isomers. Increasing starch degradability from LO to HI reduced $(P<0.01)$ daily production of trans-11 18:1, especially for the HF diet, but tended to increase $(P=0.11)$ the trans-10 isomer. Similarly, when the distribution of individual trans 18:1 positional isomers were expressed as a percentage of the total trans 18:1 outflow, increasing starch degradability from LO to HI tended $(P=$ $0.06)$ to increase the trans-10 isomer and decrease the trans-11 isomer. No starch degradability effects were found on the percentages of trans- $6 / 8$ or trans- 9 isomers. The percentage of trans-12 tended to decline $(P$ $=0.13$ ) from LO to HI, especially for the HF diet.
Increasing starch degradability tended to decrease $(P=0.08) \mathrm{mg}$ of cis-9,trans-11 CLA synthesized each day but tended to increase $(P=0.12)$ trans-10, cis-12 CLA daily production. Similarly, when CLA isomers were expressed as a percentage of total CLA, increasing starch degradability decreased $(P<0.01)$ the proportion of cis-9,trans-11 CLA but increased $(P=0.01)$ the proportion of trans-10, cis-12 CLA.

The shift in $\mathrm{BH}$ intermediates toward more trans-10 18:1 and trans-10, cis-12 CLA by increasing starch degradability in this study is consistent with a greater risk of MFD. Increased trans-10,cis-12 CLA output from the rumen travels via the blood to the mammary gland where it inhibits activation of sterol response element binding protein 1 and downregulates expression of many enzymes involved in mammary lipid synthesis (Jenkins and Harvatine, 2014). Trans-9,cis-11 CLA and cis-10,trans-12 CLA have also been reported as potential inhibitors of milk fat synthesis (Saebø et al., 2005; Perfield et al., 2007). Rumen environmental factors documented to increase ruminal synthesis of trans10, cis-12 CLA include low pH (Fuentes et al., 2009, 2011) and low dietary fiber (Gudla et al., 2012).

Increased starch degradability in the rumen was associated with reduced milk fat percentage in a metaanalysis by Ferraretto et al. (2013), who compared different corn grain harvesting and processing methods. Cows fed high moisture corn in the meta-analysis had lower milk fat percentage than cows fed dry corn (3.41 vs. $3.59 \%$, respectively). Explanations for the negative starch degradability effect on milk fat percentage seen in vivo are confounded by numerous variables including differences in intake, rumen $\mathrm{pH}$, and rumen passage rates. This study was done in continuous cultures to control all variables across a wide range of starch degradabilities. The results confirmed increased production of a CLA isomer (trans-10, cis-12) linked to MFD as starch degradability increased. This supports reports that fermented feeds with higher rates of starch degradabilities, such as corn silage or high-moisture corn, often show evidence of lower milk fat percentages (Ferraretto et al., 2013).

\section{CONCLUSIONS}

The increase of unsaturated fat in diets fed to continuous fermenters increased accumulation of $\mathrm{BH}$ intermediates. In addition, increasing starch degradability resulted in greater accumulation of CLA isomers responsible for MFD even when higher ruminal $\mathrm{pH}$ was observed. Dietary risk factors for MFD, therefore, should also include high rates of starch degradability additionally to low rumen $\mathrm{pH}$, high fat concentration, or low fiber diets. 


\section{ACKNOWLEDGMENTS}

Approved as Technical Contribution No. 6412 of the Clemson University Experiment Station. The authors thank Mark Holt of Matrix Nutrition LLC (Phoenix, $\mathrm{AZ}$ ) for donation of the processed and unprocessed corn used to prepare diets for the study and for helpful comments and discussion on experimental design and interpretation of results.

\section{REFERENCES}

Association of Official Analytical Chemists. 1990. Official Methods of Analysis. 15th ed. AOAC, Arlington, VA.

Baumgard, L. H., B. A. Corl, D. A. Dwyer, A. Saebo, and D. E. Bauman. 2000. Identification of the conjugated linoleic acid isomer that inhibits milk fat synthesis. Am. J. Physiol. Regul. Integr. Comp. Physiol. 278:R179-R184.

Broderick, G. A. 2003. Effects of varying dietary protein and energy levels on the production of lactating dairy cows. J. Dairy Sci. 86:1370-1381.

Broderick, G. A., N. D. Luchini, S. M. Reynal, G. A. Varga, and V. A. Ishler. 2008. Effect on production of replacing dietary starch with sucrose in lactating dairy cows. J. Dairy Sci. 91:4801-4810.

Chibisa, G. E., P. Gorka, G. B. Penner, R. Berthiaume, and T. Mutsvangwa. 2015. Effects of partial replacement of dietary starch from barley or corn with lactose on ruminal function, short-chain fatty acid absorption, nitrogen utilization, and production performance of dairy cows. J. Dairy Sci. 98:2627-2640.

Dijkstra, J., J. L. Ellis, E. Kebreab, A. B. Strathe, S. Lopez, J. France, and A. Bannink. 2012. Ruminal pH regulation and nutritional consequences of low pH. Anim. Feed Sci. Technol. 172:22-33.

Ferraretto, L. F., P. M. Crump, and R. D. Shaver. 2013. Effect of cereal grain type and corn grain harvesting and processing methods on intake, digestion, and milk production by dairy cows through a meta-analysis. J. Dairy Sci. 96:533-550.

Fuentes, M. C., S. Calsamiglia, P. W. Cardozo, and B. Vlaeminck. 2009. Effect of $\mathrm{pH}$ and level of concentrate in the diet on the production of biohydrogenation intermediates in a dual-flow continuous culture. J. Dairy Sci. 92:4456-4466.

Fuentes, M. C., S. Calsamiglia, V. Fievez, M. Blanch, and D. Mercadal. 2011. Effect of $\mathrm{pH}$ on ruminal fermentation and biohydrogenation of diets rich in omega- 3 or omega- 6 fatty acids in continuous culture of ruminal fluid. Anim. Feed Sci. Technol. 169:35-45.

Gerson, T., A. John, and A. S. King. 1985. The effects of dietary starch and fibre on the in vitro rates of lipolysis and hydrogenation by sheep rumen digesta. J. Agric. Sci. (Camb.) 105:27-30.

Goad, D. W., C. L. Goad, and T. G. Nagaraja. 1998. Ruminal microbial and fermentative changes associated with experimentally induced subacute acidosis in steers. J. Anim. Sci. 76:234-241.

Gudla, P., A. A. AbuGhazaleh, A. Ishlak, and K. Jones. 2012. The effect of level of forage and oil supplement on biohydrogenation intermediates and bacteria in continuous cultures. Anim. Feed Sci. Technol. 171:108-116.

Jenkins, T. C. 2010. Common analytical errors yielding inaccurate results during analysis of fatty acids in feed and digesta samples. J. Dairy Sci. 93:1170-1174.

Jenkins, T. C., W. C. Bridges Jr., J. H. Harrison, and K. M. Young. 2014. Addition of potassium carbonate to continuous cultures of mixed ruminal bacteria shifts volatile fatty acids and daily production of biohydrogenation intermediates. J. Dairy Sci. 97:975-984.
Jenkins, T. C., V. Fellner, and R. K. McGuffey. 2003. Monensin by fat interactions on trans fatty acids in cultures of mixed ruminal microbes grown in continuous fermenters fed corn or barley. J. Dairy Sci. 86:324-330.

Jenkins, T. C., and K. J. Harvatine. 2014. Lipid feeding and milk fat depression. Vet. Clin. North Am. Food Anim. 30:623-642.

Krause, K. M., and D. K. Combs. 2003. Effects of forage particle size, forage source, and grain fermentability on performance and ruminal pH in mid lactation cows. J. Dairy Sci. 86:1382-1397.

Latham, M. J., J. E. Storry, and M. E. Sharpe. 1972. Effects of lowroughage diets on the microflora and lipid metabolism in the rumen. Appl. Microbiol. 24:871-877.

Martel, C. A., E. C. Titgemeyer, L. K. Mamedova, and B. J. Bradford. 2011. Dietary molasses increases ruminal $\mathrm{pH}$ and enhances ruminal biohydrogenation during milk fat depression. J. Dairy Sci. 94:3995-4004

Mathew, B., M. L. Eastridge, E. R. Oelker, J. L. Firkins, and S. K. R. Karnati. 2011. Interactions of monensin with dietary fat and carbohydrate components on ruminal fermentation and production responses by dairy cows. J. Dairy Sci. 94:396-409.

McCormick, M. E., D. D. Redfearn, J. D. Ward, and D. C. Blouin. 2001. Effect of protein source and soluble carbohydrate addition on rumen fermentation and lactation performance of Holstein cows. J. Dairy Sci. 84:1686-1697.

Nagaraja, T. G., and E. C. Titgemeyer. 2007. Ruminal acidosis in beef cattle: The current microbiological and nutritional outlook. J. Dairy Sci. 90(E. Suppl.):E17-E38.

Perfield, J. W. II, A. L. Lock, A. Sæb $\varnothing$, J. M. Griinari, D. A. Dwyer, and D. E. Bauman. 2007. Trans-9, cis-11 conjugated linoleic acid (CLA) reduces milk fat synthesis in lactating dairy cows. J. Dairy Sci. 90:2211-2218.

Qiu, X., M. L. Eastridge, K. E. Griswold, and J. L. Firkins. 2004. Effects of substrate, passage rate, and $\mathrm{pH}$ in continuous culture on flows of conjugated linoleic acid and trans-C18:1. J. Dairy Sci. 87:3473-3479.

Ramirez Ramirez, H. A., E. Castillo Lopez, K. J. Harvatine, and P. J. Kononoff. 2015. Fat and starch as additive risk factors for milk fat depression in dairy diets containing corn dried distillers grains with solubles. J. Dairy Sci. 98:1903-1914.

Rico, D. E., S. H. Preston, J. M. Risser, and K. J. Harvatine. 2015 Rapid changes in key ruminal microbial populations during the induction of and recovery from diet-induced milk fat depression in dairy cows. Br. J. Nutr. 114:358-367.

Saeb $\varnothing$, A., P. C. Saebo, J. M. Griinari, and K. J. Shingfield. 2005. Effect of abomasal infusions of geometric isomers of 10,12 conjugated linoleic acid on milk fat synthesis in dairy cows. Lipids 40:823-832.

Slyter, L. L., M. P. Bryant, and M. J. Wolin. 1966. Effect of pH on population and fermentation in a continuously cultured rumen ecosystem. Appl. Microbiol. 14:573-578.

Stokes, S. R., W. H. Hoover, T. K. Miller, and R. P. Manski. 1991. Impact of carbohydrate and protein levels on bacterial metabolism in continuous culture. J. Dairy Sci. 74:860-870.

Teather, R. M., and F. D. Sauer. 1988. A naturally compartmented rumen simulation system for the continuous culture of rumen bacteria and protozoa. J. Dairy Sci. 71:666-673.

Van Nevel, C. J., and D. I. Demeyer. 1996. Influence of pH on lipolysis and biohydrogenation of soybean oil by rumen contents in vitro. Reprod. Nutr. Dev. 36:53-63.

Van Soest, P. J., J. B. Robertson, and B. A. Lewis. 1991. Methods for dietary fiber, neutral detergent fiber, and nonstarch polysaccharides in relation to animal nutrition. J. Dairy Sci. 74:3583-3597.

Zened, A., F. Enjalbert, M. C. Nicot, and A. Troegeler-Meynadier. 2013. Starch plus sunflower oil addition to the diet of dry dairy cows results in a trans-11 to trans-10 shift of biohydrogenation. J. Dairy Sci. 96:451-459. 